\title{
El presente en suspenso. Estratos del tiempo y la pregunta por lo contemporáneo a partir del pensamiento de Reinhart Koselleck
}

\author{
Suspended present. Temporal layers and the question about the \\ contemporary according to Reinhart Koselleck
}

LUCILA SVAMPA*

\begin{abstract}
Resumen: Los intentos por aprender de la historia considerando las "lecciones" que ofrece abren un amplio terreno de discusión sobre los modos de aproximarnos a ella. Ahora bien, cuando nos referimos a eventos traumáticos, las demandas por superar el pasado dejando atrás viejas disputas presuponen una reivindicación de una estructura cronológica de las dimensiones temporales. En el futuro trabajo buscaremos explorar dicho punto de partida, indagando sobre alternativas centradas en una resignificación de los modos en que comprendemos la historicidad. Esto se llevará adelante estudiando principalmente la noción de estratos del tiempo propuesta por el historiador alemán Reinhart Koselleck y formulando el impacto que esto tiene no solo para pensar el pasado, sino también el presente y el futuro.
\end{abstract}

Palabras clave: historia - estratos - tiempo.

\begin{abstract}
The efforts to learn from the history considering the "lessons" that it offer, open a vast field of discussion about the ways in which we approach us to it. Though, when we refer to traumatic events, the claims to overcome the past leaving behind old disputes, suppose a chronological structure of the temporal dimensions. In the future paper, we will aim to explore that starting-point, inquiring alternatives focused in a resignification of the ways in which we understand history. This will be possible through a study of the notion of temporal layers, holed by the German historian Reinhart Koselleck, and at the same time, framing the impact that this has not only to think in the past, but also the present and the future.
\end{abstract}

Key words: history - layers - time.

\section{Introducción}

Hace ya más de treinta años, el recientemente fallecido Ernst Nolte (1986) lanzó en un artículo la célebre fórmula "Die Vergangenheit, die nicht vergehen will" ("El pasado que no quiere pasar"), con la que daría inicio al famoso Historikerstreit (debate de los historiadores).

Fecha de recepción: 25/09/2015. Fecha de aceptación: 11/12/2016.

* Lucila Svampa es Doctora en Ciencias Sociales y Lic. en Ciencia Política por la Universidad de Buenos Aires. Se desempeña como docente de Teoría Política Contemporánea (UBA) y como becaria postdoctoral del CONICET en el Instituto de Investigaciones Gino Germani. Recientemente publicó el libro La historia en disputa. Memoria, olvido y usos del pasado (Colección de Teoría e Historia, Prometeo) y El concepto de crisis en Koselleck. Polisemias de una categoría histórica en Anacronismo e Irrupción, Revista de Teoría y Filosofía Política. lucilasvampa@gmail.com 
En un contexto de revitalización de las discusiones en torno a los modos de rememoración del Tercer Reich, este historiador alemán aludía al problemático modo en que dicho pasado -a diferencia de otros- demostraba su excepcionalidad por permanecer fuera de su tiempo, cual espectro que rodea a los vivos en el presente ${ }^{1}$. No se trataría de un acontecimiento de la historia al que "le es lícito" habitar la actualidad de modo productivo, como sí lo hacen los hitos fundacionales. La referencia a un momento que reclama desaparecer de la contemporaneidad, es decir, no insistir turbando el presente, alerta sobre el recuerdo de una etapa de la historia que se hace cada vez más fuerte. Según Nolte, este, al despertar malestares en la sociedad, se escapa del alcance de los historiadores. Esta consigna encierra provocadores presupuestos que vale la pena recuperar. Aquí sostendremos que la idea de una "sana superación del pasado" funciona muchas veces como un eufemismo para promover políticas de olvido y de impunidad en nombre de la quimérica reconciliación de un pueblo dado.

Ante este escenario, nos proponemos abrir a otras posibilidades las premisas que protagonizan dichas contiendas teóricas, apostando por el valor del conflicto y no por el silencio de un acuerdo reconciliador. Esto lo haremos revisando dichas fórmulas y poniendo especial atención en la estructura direccional del tiempo en que se basa la proclama por la superación del pasado. Para ello será fundamental referirnos a las reflexiones de Koselleck sobre el tiempo histórico. Aunque este no participó de la polémica de los historiadores en los años ochenta por resultarle de un schaler Geschmack (sabor insípido) ${ }^{2}$, es posible recuperar muchas de sus conceptualizaciones para repensar algunos de los aspectos que se derivan de dicho debate ${ }^{3}$. En este sentido, la metodología del presente trabajo se orientará a iluminar ciertos elementos problemáticos que se derivan de la defensa de una estructura cronológica para leer la historia, a través de la mirada de Koselleck. En función de ello, procederemos mediante tres pasos. En primer lugar, luego de contextualizar las denuncias de Nolte, trabajaremos sobre la noción de Zeitschichten y su triple relación con la experiencia. Luego, pondremos en el centro de la escena la definición de presente, sirviéndonos nuevamente de

1 La formulación de este tipo de expresiones no se dirige exclusivamente al nacionalsocialismo. Si se lleva la mirada al plano latinoamericano, no es difícil notar que muchos intelectuales exigieron dejar pasar el pasado dictatorial en distintos países del Cono Sur, en el momento en que se reavivaron discusiones sobre el enjuiciamiento a perpetradores y represores de los últimos gobiernos militares.

2 En una entrevista con Renata Solbach, Koselleck (2003) afirma: "Como dije, no formé parte y todo el debate de los historiadores me pareció algo tan escenificado, que es bochornoso. Fue una arrogancia ególatra, que en vistas de las preguntas que formaban parte del debate, fue casi de mal gusto, grosera y de mal gusto. "De sabor insípido" es la fórmula correcta". La traducción es mía, el original dice: "Ich habe mich, wie gesagt, nicht beteiligt und halte den ganzen Historikerstreit für so inszeniert, dass es nur peinlich ist. (...) Es war eine selbstgezüchtete Überheblichkeit, die in Anbetracht der Fragen, die zur Debatte stehen, fast geschmacklos war, taktlos und geschmacklos. >Schaler Geschmack< ist die richtige Formulierung” (Koselleck, 2003: párr. 68). Es importante mencionar que tras algunas declaraciones que allí hace, Koselleck relativiza los ataques a Nolte, apuntando a la importancia de la pregunta que este formula sobre la influencia de la URSS en el modo de pensar de los alemanes.

3 Este debate sí es analizado por otros historiadores cercanos a la teoría del tiempo histórico propuesta por Koselleck; uno de ellos es su discípulo Lucian Hölscher (2008 y 2009). Por un lado, en el segundo capítulo de Semantik der Leere, este historiador dedica dos textos a los modos en que se recuerda el pasado nazi (Eine Funktionsanalyse im Anschluss an den »Historikerstreit « um die Einmaligkeit der nationalsozialistischen Verbrechen, de 1989, y Vom richtigen Umgang mit der nationalsozialistischen Vergangenheit - zehn Jahre später, de 1999). Por otro lado, en Political Correctness: der sprachpolitische Streit um die nationalsozialistischen Verbrechen, reúne reflexiones de distintos intelectuales que analizan el asunto. 
precisiones que ofrece Koselleck pero también dirigiendo nuestra atención a la pregunta por lo contemporáneo planteada por Agamben. Finalmente, buscaremos articular los contenidos recorridos en vistas de ofrecer una lectura alternativa sobre la demanda de dejar pasar el pasado. En suma, el objetivo del presente trabajo será no solo restituir las nociones del escritor de marras sobre los modos de leer la historia, sino además articularla con una discusión concreta sobre las lecturas del pasado. De lograrse esto, se conseguiría contrastar su investigación teorética, basada en conceptos antropológicos, con una controversia particular, de la que no formó parte.

\section{El Historikerstreit y la superación del pasado}

Los cuestionamientos en torno a los modos en que las sociedades recuerdan sus pasados traumáticos han sido materia de variadas producciones. En el caso europeo, la experiencia extrema de la Shoah suscitó múltiples disputas que enfrentaron -y enfrentan- a las comunidades a grandes desafíos. La temprana pregunta de Adorno en 1959 sobre Was bedeutet: Aufarbeitung der Vergangenheit? (¿qué significa la superación del pasado?) anticipa reacciones como la de Nolte (1986), representativas de un gran sector de la intelectualidad que se expresa sobre el tema ${ }^{4}$. El momento político en que se difunde dicho texto estaba habitado por una revigorización de los debates en relación a las regulaciones memoriales previas al proceso de reunificación alemana ${ }^{5}$. Es importante destacar que esas intervenciones estatales -tanto "reglamentarias", esto es, que remiten a medidas legislativas que exigen un cumplimiento, como "indicativas", es decir, recursos más bien simbólicos (Johann, 2010)no tuvieron lugar aisladamente, sino muy por el contrario, estuvieron acompañadas por iniciativas académicas, artísticas y de la sociedad civil. Mas las pugnas por la lectura del nacionalsocialismo no siempre tuvieron un nivel de exposición tal. A los enjuiciamientos más importantes de la posguerra, le sucedió una etapa en la que prevaleció el silencio respecto de los crímenes perpetrados en los campos; sin embargo, con el correr de los años se despertaron paulatinamente nuevos interrogantes que se instalaron en la esfera pública ${ }^{6}$. Así, en el plano historiográfico fueron muchas las interpretaciones que se orientaron a escribir y por ende comprender el fenómeno. De acuerdo al trabajo del historiador italiano Enzo Traverso (2012), en un principio, este tema aparecía notoriamente diferenciado de las investigaciones centradas en la Shoah. Durante los años cincuenta predominaban teorías que aludían a la responsabilidad del Führer, como quien había sometido a la sociedad en el marco del totalitarismo que imperaba. Años más tarde, las indagaciones contemplaron otros

4 Tal vez uno de los casos más emblemáticos sea el de Todorov (2000), quien alerta sobre los abusos de la memoria en la actualidad. Reivindicando el olvido, el escritor opta por una mémoire exemplaire (memoria ejemplar), que ponga un límite al frenesí memorialista de nuestra época.

5 La normalización de la nación primó como una necesidad tanto en el momento de la posguerra como en el de la reunificación. La imagen que Alemania debía dar de un Estado democrático y consolidado institucionalmente influyó a nivel internacional. Los procesos de rememoración con respecto al nazismo, que incluyeron juicios, reparaciones económicas y medidas contra el negacionismo buscaban darle al país una imagen confiable. Sobre este tema, ver Jelin (2006) y Rauschenberg (2016).

6 Para una etapización de los modos de rememoración del nacionalsocialismo desde la posguerra hasta la unificación, ver Svampa (2016). Sobre las transformaciones en los debates en el ámbito universitario alemán, ver Gay (2015). 
vínculos entre la sociedad alemana y el nazismo, para finalmente, en los ochenta integrar también el Holocausto entre las variables analíticas más relevantes, momento a partir del cual la ideología nazi no sería estudiada sin dirigir la mirada al mismo tiempo al exterminio de los judíos.

En dicho contexto aparece el artículo en el periódico alemán Frankfurter Allgemeinen Zeitung, en el que Nolte insiste en la espectralidad del pasado nacionalsocialista. Tras esta publicación, se genera una profunda discusión, cuya piedra angular serán dos textos de Habermas (2000 y 1997) en los que se pone en jaque la comparabilidad del Holocausto y se dan lugar a debates en torno a la normalización de Alemania como nación y a los sentidos susceptibles de ser atribuidos al tiempo pasado ${ }^{7}$. Las intervenciones tuvieron además como protagonistas a Andreas Hillgruber, Klaus Hildebrand y Michael Stürmer y lograron conmover a la sociedad alemana incluso más allá del ámbito de la historiografía, movilizando polémicas en torno a la culpa, la responsabilidad, la identidad y la superación del pasado nazi.

Podríamos resumir la postura de Nolte, que es la que aquí más nos interesa, en dos puntos: en la falta de interés por los problemas del presente y en la comparabilidad del fenómeno. En primer lugar, a pesar de que este intelectual admite que los historiadores no pueden garantizar que se aprenda de la historia, muestra una profunda insatisfacción con el modo en que estos analizan dicho período. La obstinación en no superar dicho pasado reside, entre otras cosas, en un posible interés que las víctimas o sus familiares tienen en la desviación de la atención general, que hace que revisitemos una y otra vez dichos eventos en lugar de llevar nuestra mirada a las atrocidades actuales, como las que sucedían en Afganistán o en Vietman por aquel entonces. Si bien con la consolidación del Estado democrático, los crímenes perpetrados y el belicismo nazi representan ya un evento lejano, la sociedad seguía alerta por la creciente carrera armamentística de las potencias. Siguiendo a Nolte, menos fructífero aún es hablar de la culpa de los alemanes -cuando quienes lanzan dicha acusación son ajenos a los hechos-, de antisemitismo -algo que no reconoce sus profundas raíces ni muestra dicho sentimiento entre los polacos mismos-y de víctimas -sin mencionar que los oficiales de las SS también lo fueron.

En segundo lugar, sostener que la Solución Final debe ser tratada como una excepcionalidad, no le permite "pasar" donde le corresponde: "Para el historiador se encuentra aquí la consecuencia más lamentable de «no pasar» del pasado: que las reglas más simples, válidas para cualquier pasado, parece que dejan de tener vigencia en este caso" (Nolte, 2007: 73). El argumento principal de Nolte es que Alemania había reaccionado legítimamente ante la amenaza del comunismo soviético, cuyo avance violento influyó en el devenir político nazi: “¿acaso llevaron a cabo Hitler y los nacionalsocialistas un crimen «asiático» únicamente porque ellos y sus iguales se consideraban víctimas reales o potenciales de un crimen «asiático»? ¿No fue el Archipiélago gulag anterior a Auschwitz? El «asesinato de clase» perpetrado por los bolcheviques, ¿no fue la premisa lógica y fáctica del «asesinato racial» perpetrado por los nacionalsocialistas?" (Nolte, 2007: 74). Esta es sin dudas la variable argumentativa que

7 Hay mucha literatura instructiva al respecto. Por caso, Maier (1998) reconstruye las principales líneas de discusión al respecto y atenúa la doble alternativa entre comparabilidad y unicidad para analizar los crímenes nazis. Es destacable también la intervención de Wehler (1988), tal vez una de las más difundidas e ilustrativas de su época. 
más nos compete, ya que se sostiene en una partición de temporalidades, cuyos elementos se caracterizarían por poseer una estabilidad y homogeneidad incuestionable.

Estas afirmaciones constituyen entonces un alegato en favor de librarse del pasado, ya que aducen que este es responsable de pesadas cargas que atentan contra el "normal" funcionamiento de las comunidades políticas. A diferencia de otros acontecimientos pasados, el recuerdo del Tercer Reich vendría a inhibir la potencialidad de nuestras acciones, amenazadas eternamente por un tiempo pretérito: "El pasado nacionalsocialista en cambio -como subrayaba hace poco Hermann Lübbe- aparentemente no se encuentra tocado por este proceso de desaparición, de debilitamiento, sino que parece todavía vivo y vigoroso, pero no como modelo, sino como espantajo, como un pasado que se hace casi presente o que pende sobre nuestra época como si se tratase de una espada de Damocles” (Nolte, 2007: 71). Así, se presupone que en la tarea de superar el pasado prevalece un componente cronológico. Esto es: culminar con la vitalidad de ciertas heridas que habitan el tiempo pretérito implica ubicar dicha etapa en su lugar, a saber: atrás, espacio que le correspondería indagar a los historiadores.

\section{Sobre la contemporaneidad de lo histórico}

De cualquier modo, para explorar las interpretaciones de los acontecimientos históricos, no sólo resulta fértil la labor historiográfica de remitirnos a fuentes y archivos, sino más aún, a lo que Koselleck llamó Historik, esto es, una teoría de la historia que atienda a las condiciones de producción de los discursos históricos ${ }^{8}$. Esto último no requiere eliminar la contingencia, sino más bien enmarcarla en una reflexión sobre el decurso de la temporalidad en la que se define nuestra historicidad.

Las teorizaciones que se expresaron en dicho sentido tuvieron una fuerte influencia del hegelianismo, que planteaba una realización progresiva y objetiva de la Idee. Pero el distanciamiento de la historia magistra vitae fue acompañado de reformulaciones al interior de la filosofía de la historia, en las que podemos apoyarnos si buscamos una alternativa a los órdenes secuenciales en los que se basan los proyectos que arriba definimos. En este contexto, dado que los acercamientos a la historia demostraron no responder a un único vector, las distintas lecturas del pasado se basan en la presunción de que los valores con los que lo juzgamos varían en el tiempo. Esto tiene como consecuencia, entre otras cosas, el hecho de que el abandono de un progreso que indique posibles avances o retrocesos nos deja desprovistos de una guía para ordenar los sucesos. Ahora ya no se adecuarán más al registro de un antes y un después, sino que irrumpirán como posibles coexistencias, algo que Koselleck denominó -apoyándose en Bloch-die Gleichzeitigkeit des Ungleichzeitigen (la contemporaneidad de lo no contemporáneo) ${ }^{9}$. Esto no puede explicarse si no atendemos

8 Este neologismo, tomado de Droysen, le permite a Koselleck distinguirlo de die Geschichte, término germano que remite a los acontecimientos y sucesos pasados, y de die Historie, vocablo según el escritor, de origen

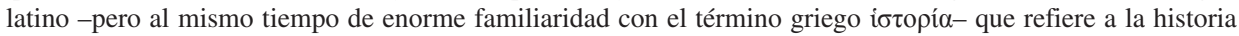
como reflexión sobre sí misma. Koselleck (2010) analiza en una entrada de los Geschichtliche Grundbegriffe la relación entre ambas voces.

9 El célebre pasaje de Erbschaft dieser Zeit versa: "Nicht alle sind im selben Jetzt da. Sie sind es nur äußerlich, dadurch, daß sie heute zu sehen sind. Damit aber leben sie noch nicht mit anderen zugleich” (Bloch, 1962: 104). 
a un modo muy particular de relacionarnos con la temporalidad, que según nuestro escritor, se inaugura en la Modernidad. Como comentan los catedráticos Oncina y Villacañas: "Esta metafórica permite entender que sean contemporáneos estratos de contenido conceptual no contemporáneo (FP, pág. 123), que determinados supuestos pragmáticos necesarios para el uso significativo de nuestros términos ya no se den en el presente histórico. El término sería contemporáneo, pero el contexto pragmático — identificado por la historia social— necesario para su uso sería inexistente" (Oncina y Villacañas, 1997: 44).

Con el propósito de eludir el binomio linealidad-circularidad con el que los historiadores han interpretado el tiempo, Koselleck plantea una alternativa teórica centrada en los Zeitschichten (estratos del tiempo), que en lugar de excluir repetición y direccionalidad, compromete ambas. Mientras que el primero es asociado a un despliegue teleológico, forjado principalmente a partir del idealismo alemán y del movimiento de la Ilustración, el segundo se vincula a la recurrencia de las experiencias ${ }^{10}$. Si bien esta perspectiva tiene su origen en los griegos, encontró un posterior desarrollo principalmente a través de la noción nietzscheana de ewige Wiederkehr des Gleichen (eterno retorno de lo mismo). Koselleck aclara que este último esquema también puede pensarse linealmente si se presupone un final desde el principio del movimiento. Adicionalmente habrá que considerar la experiencia: el autor ofrece un juego de palabras entre erfahren (experimentar) y fahren (viajar/andar) en el que pliega la primera a la definición griega de historia, para concluir que la experiencia histórica remite siempre a un movimiento en el que se produce un "viaje de descubrimiento" (Koselleck, 2001: 36) ${ }^{11}$. La experiencia será, así, un factor con el que analizar la vida de los Zeitschichten.

La metáfora de los estratos se basa en un término proveniente de la geología, que permite describir "diferentes niveles temporales en los que se mueven las personas, se desarrollan los acontecimientos o se averiguan sus presupuestos de larga duración” (Koselleck, 2001: 35). Para acceder a tal definición, el autor propone distinguir tres aspectos: la unicidad, las estructuras de repetición y los estratos. El primero de ellos es el de la experiencia de la Einmaligkeit (unicidad), que representa situaciones tanto biográficas como históricas, en las que los acontecimientos se muestran como sorprendentes e irreversibles, y que obligan a reactualizar la experiencia temporal ${ }^{12}$. Luego, afirma la existencia de una Wiederholungsstruktur (estructura de repetición) en los fenómenos no solo históricos sino también jurídicos o lingüísticos, que no se agotan en una unicidad. Esto se ejemplifica con una situación cotidiana: si bien cada carta que recibimos contiene una novedad, esto es posible por la regularidad con la que el cartero viene a nuestras casas. En otras palabras: "Sin retorno de lo mismo -al menos de lo análogo en la planificación- y sin organización es imposible realizar acontecimientos únicos" (Koselleck, 2001: 37).

10 Vale la pena destacar que Koselleck marca una diferencia entre Herder y Kant. Afirma que mientras que este definía un tiempo a priori, aquél rechazaba la idea aduciendo diferentes temporalidades para cada ser.

11 Esta analogía está presente también en el texto de Heidegger sobre Hegel y en el diccionario de los hermanos Grimm. La entrada de erfahren de este último señala una cercanía con un viaje de exploración en el que el protagonista se acerca a peligros (Gefahren) y que conoce por medio de un movimiento.

12 La unicidad se produce por la sorpresa que genera cuando hay una discontinuidad en un continuum temporal, en el que no se corresponden las expectativas venideras con las experiencias previas. Según el intelectual alemán, cuando hay una iterabilidad en los fundamentos que definen los acontecimientos, estos se pueden explicar. De allí que las personas mayores cuenten con una experiencia acumulada que hace que pocas cosas las sorprendan, algo que puede llevar, según Koselleck, a la arrogancia. 
Ahora bien, si la estabilidad de las estructuras es invariable, ¿entonces cómo pensar el cambio en la historia? La respuesta de Koselleck dice: es posible que las estructuras se modifiquen, por esta razón no se trata de estructuras eternas, sino de larga duración. De modo que si hasta ahora dijimos que dentro de la unicidad hay repetición, habrá que admitir que también en la repetición hay unicidad. Esto último explica que la recurrencia de los fenómenos sea modificable: "La ganancia de una teoría de los estratos del tiempo consiste por lo tanto en poder medir distintas velocidades aceleraciones o demoras, y hacer así visibles distintos modos de cambio que ponen de manifiesto una gran complejidad temporal" (Koselleck, 2001: 38). Esta caracterización capta los diversos movimientos paralelos que ocurren a partir de un mismo suceso histórico. Para ejemplificar esta situación, nada mejor que los cambios producidos tras la caída del muro de Berlín: si bien ambas partes de Alemania se unificaron constitucional, institucional y jurídicamente, no se integraron económicamente ni a nivel de las mentalidades de los ciudadanos, de modo que "cualquier investigación empírica exige aquí, al menos implícitamente, una teoría del tiempo que trabaje con varios estratos" (Koselleck, 2001: 39). No es difícil establecer una analogía con el pasado nacionalsocialista al que Nolte aludía. Más allá de que una vez terminada la Segunda Guerra Mundial, en Alemania institucionalmente se haya establecido un gobierno democrático, que se haya enjuiciado a los principales oficiales nazis, que se hayan resuelto compensaciones económicas para víctimas o familiares de víctimas, el sufrimiento de quienes experimentaron los campos y las preguntas de nuevas generaciones que buscan explicaciones sobre lo sucedido, no pueden despacharse de un momento a otro.

La convivencia de estos dos niveles nos permite apreciar no solo las novedades que nos sorprenden en ese desfasaje entre experiencias y expectativas, sino también las condiciones de posibilidad de ese suceso. Respecto del primer punto, en ocasión de su estudio sobre la llegada de la Neuzeit (modernidad), Koselleck (1993) apela a la centralidad del hiato entre el Erfahrungsraum (espacio de experiencia) y el Erwartungshorizont (horizonte de expectativas). Tal situación indica un momento de cambios y por ende de crisis, en el que se redefinen las connotaciones de los conceptos por atravesar un proceso de democratización, politización, temporalización e ideologización. En tanto punto de intersección entre un devenir cargado de esperanzas y la tradición de la que proviene, esta circunstancia pone en evidencia mutaciones en las percepciones del mundo. En ese desgarramiento se producen las luchas por las reapropiaciones de los sentidos de los conceptos, algo que el autor bautiza como Kampfbegriff.

En cuanto al segundo aspecto, este se refiere no sólo a qué ocurrió -para lo cual habría que poner el foco en la unicidad-, sino cómo fue posible que ocurra -donde las fuentes principales serán las estructuras de repetición. El encuentro de estos dos factores nos permite entonces concentrarnos en un hecho del pasado sin por esos pecar de miopes. Si quisiésemos buscar una clave interpretativa para superar un momento crítico de la historia, deberíamos entonces dirigir la mirada a un plano más amplio y remitirnos a los motivos que enmarcaron su desarrollo, extendiendo el alcance del análisis ${ }^{13}$. Estas razones deberían

13 Existen otros pensadores de la historia que han abordado la cuestión de los planos. Por caso, Kracauer (2010) afirma que la ampliación de tomas de los acontecimientos ofrece enfoques diferentes al conjugar los primeros planos con la visión del conjunto, poniendo en juego la tensión entre las escalas micro y macro de las historias. 
rastrearse en las disposiciones de un determinado contexto que nos puedan decir cómo en cierta época se configuraron las condiciones para que emerjan subjetivaciones específicas que lleven adelante concretos procesos históricos. Dicho esto, podemos incorporar a nuestro análisis otro elemento que evoca Koselleck: el generacional. Para tener conocimiento de las estructuras de repetición, se requiere experiencia, algo que según él -y esto es, por cierto discutible-, se adquiere con el paso del tiempo en la vida de las personas. De modo que hay una limitación biológica que dicta que cada generación será capaz de procesar una cantidad finita de experiencias. No es difícil pensar en esta instancia en la importancia de una comunicación intergeneracional, que si bien nunca podrá transmitir una memoria viva de aquello que algunos vivieron, sí podrá hacer de su relato un acervo colectivo ${ }^{14}$. Mas el recaudo de no homologar ambos registros debe ser una máxima si no se quiere caer en un peligroso error, puesto que según nuestro escritor, todo tipo de memoria colectiva que busque instalar públicamente un recuerdo en torno a un evento del pasado no es más que una falacia bienintencionada:

La experiencia marcada a fuego en el cuerpo de la absurda ausencia de sentido como experiencia primaria no puede llevarse a la memoria de otros ni al recuerdo de los no afectados. Los contemporáneos y los pertenecientes a generaciones posteriores hemos de aprender a tratar con este legado negativo (Koselleck, 2011: 55-56).

Koselleck afirma la imposibilidad de transferir las experiencias primarias, "pues precisamente lo que caracteriza a la experiencia es ser intransferible, en eso consiste la experiencia" (Koselleck, 2011: 40). El escritor recurre a una vivencia personal para describir esta definición. Cuenta que, como oficial en la Segunda Guerra Mundial, cuando fue prisionero de los rusos, oyó hablar por primera vez de lo que había sucedido en Auschwitz y en Birkenau. Si bien en principio ni él ni sus compañeros creían en lo que los rusos relataban, el exterminio se volvió claro luego de una experiencia única: al resistirse a las órdenes de pelar con prisa papas que los rusos comerían, su guardián polaco (que había sido prisionero en un campo de concentración) tomó un banco, lo alzó y antes de arrojarlo y romperlo, dijo "Quieres que te rompa el cráneo, vosotros habéis gaseado a millones” (Koselleck, 2011: 40). Esta vivencia cambió por completo su perspectiva de las cosas.

En la tarea de la reelaboración del pasado, la transmisión se revela como un remedio al posible olvido de ciertas vivencias, provocado por el paso del tiempo. En este contexto, la tercera parte que Koselleck señala para el análisis histórico, son los geschichtliche Schichten

En todo caso, siempre que se trate de perspectivas, los planos son relativos. Los vínculos con el cine no son difíciles de marcar, en especial, con la película Blow up, basada en un cuento de Cortázar.

14 Frente al auge de las conceptualizaciones sobre la memoria colectiva, que surgen fundamentalmente como continuaciones de las investigaciones de Halbwachs (2004 y 1997), Koselleck (2011) hace un elogio a la memoria individual, sirviéndose del término negatives Gedächtnis (memoria negativa). En una entrevista, el historiador alemán aclara su posición: "Y mi posición personal en este tema es muy estricta en contra de la memoria colectiva, puesto que estuve sometido a la memoria colectiva de la época nazi durante doce años de mi vida. Me desagrada cualquier memoria colectiva porque sé que la memoria real es independiente de la llamada «memoria colectiva», y mi posición al respecto es que mi memoria depende de mis experiencias, y nada más. Y se diga lo que se diga, sé cuáles son mis experiencias personales y no renuncio a ninguna de ellas (Koselleck en Fuentes y Sebastián, 2006: 6). 
(estratos históricos) mismos, que captan las experiencias que exceden las de los individuos y generaciones. Estos son trascendentes, no porque se fundamenten en un componente extramundano, sino porque forman parte de un entramado social mucho más amplio, que refiere a cosmovisiones preexistentes y sobrevivientes a las generaciones. Este aspecto nos permite iluminar formas más generales en las que se gestan los acontecimientos.

En suma, presentando estos tres estratos (unicidad, estructuras de repetición y estratos históricos), Koselleck altera significativamente el modo en que pensamos el tiempo. La propuesta de una cartografía que propone el encuentro diacrónico de capas temporales suma nuevas dimensiones a las que debemos atender si queremos estudiar con atino los acontecimientos del pasado. De modo que la alternativa de leer o no al nacionalsocialismo como una excepción puede ser reformulada por un lado, pensándose los diversos aspectos que forman parte de dicho fenómenos (a saber, el antisemitismo, los mecanismos institucionales previstos por la constitución de Weimar, la complicidad civil, de los sectores económicos y de la Iglesia, las condiciones de pobreza de la primera posguerra, y las responsabilidades de un líder totalitario) en tanto unicidades que tienen lugar dentro de estructuras de repetición y de estratos históricos mucho más amplios que la Alemania de los años treinta. Por otro lado, lo anterior nos permitiría comprender la convivencia de algunos de estos niveles con lo contemporáneo por la certeza de que muchos de ellos no se agotaron al terminar la Segunda Guerra Mundial. Que cada uno se mueva con diversas velocidades, muestra sus múltiples devenires y posibles encuentros en las distintas dimensiones temporales.

\section{Temporalización del presente}

Ahora bien, si este nuevo análisis fractura el esquema de un tiempo homogéneo, no solo el modo en que abordamos el pasado demanda un cambio, sino también en que nos acercamos al presente y al futuro. Desde aquí en más, ya no será evidente dónde ubicar los límites entre lo que pertenece al pasado y lo que no, ni tampoco podremos hacerlo sin una justificación metodológica que evidencie la productividad de tal división. Vimos que Nolte hablaba de un pasado que permanece vivo y reclama reelaboraciones, de un pasado que no pasa. Dice: ese pasado está fuera de lugar; tomando prestado el término de Shakespeare, podríamos decir también out of joint (fuera de quicio). En otras palabras, el mundo está patas para arriba, desorientado. Un tiempo con sus órdenes corrompidos de un modo tal, nos insta a ajustarlo. Pero si quisiésemos por el contrario, sostener que podemos leer este fenómeno en clave de una simultaneidad no conflictiva, deberíamos definir qué significa que un evento nos sea actual. En un artículo de 1988, titulado Stetigkeit und Wandel aller Zeitgeschichten, Koselleck se pregunta qué significa el presente y ofrece dos definiciones extremas, que descarta rápidamente. La primera, lo caracteriza como un punto de intersección con el pasado y el futuro, según lo cual "el presente está condenado a la desaparición" (Koselleck, 2001: 116). La segunda acepción se basa en la premisa de que en tanto el pasado ya sucedió y el futuro no llegó, el presente es el único tiempo. Mas es necesario contemplar que "hay dimensiones, de carácter diacrónico y sincrónico, que se inscriben en distintas profundidades" que se pueden ilustrar con "ejemplos que dan testimonio del pasado pasado como presente pasado” (Koselleck, 2001: 131). Gracias a algunos casos que acercan problemas planteados 
en la Antigua Grecia a situaciones del siglo XX, el escritor señala la recurrencia de los fenómenos, que demuestran a las claras una mutua pertenencia entre las distintas épocas.

Ante los aprietos en los que nos dejan estas dos definiciones provenientes del uso convencional, Koselleck propone un experimento por el cual se temporalizarían pasado, presente y futuro. Esto da como resultado tres combinaciones: tenemos, en primer lugar, un pasado presente y un futuro presente (siendo este último o bien aquel que determina las otras dos dimensiones aportando una cierta estabilidad o bien aquel que se desvanece); luego, un presente pasado con sus correspondientes pasados pasados y sus futuros futuros (algo posible por una expansión hacia adelante y hacia atrás del futuro); finalmente, hay un presente futuro con su pasado futuro y su futuro futuro (Koselleck, 2001: 118). Esto le permite concluir a Koselleck que la historia siempre es historia del tiempo presente. En este contexto, Dauer (duración), Wechsel (cambio) y Einmaligkeit (unicidad) se conjugan sobre la base de una materialidad política concreta y por tanto expresa obligadamente una posición:

Lo que tiene duración alcanza, por ejemplo, desde un presente pasado (no desde un pasado pasado) hasta el futuro presente, quizás hasta el futuro futuro. El cambio puede igualmente establecerse como el tránsito desde un pasado pasado a un presente pasado (piénsese por ejemplo en las instituciones feudales y su disolución en el curso de la secularización o en la liberación de los agricultores) o desde el futuro pasado de mundos anteriores hasta nuestro pasado presente (piénsese por ejemplo en las utopías de la Revolución francesa, cuyas esperanzas todavía están presentes). La unicidad se deriva de la sucesión de los presentes con sus pasados y futuros que se modifican (Koselleck, 2001: 119).

De modo que la formalización de los contenidos que pertenecen a distintas secuencias temporales vuelve a esas materias móviles. Pero esa movilidad no dependerá de un registro teleológico ni de orden trascendental, sino más bien de quienes interpretan, lo que en este contexto, es lo mismo que decir que es contingente. Como advierte Kant en Der Streit der Facultäten, una historia a priori solo es posible cuando su Wahrsager (adivino) produce los sucesos mismos que pronostica ${ }^{15}$. En tanto los contenidos temporales pueden circular por distintos niveles, es posible admitir varias definiciones del presente, incluso contemporáneas entre sí, que son las que nos ofrecen un punto de apoyo, en el sentido de que proveen una perspectiva desde la cual interpretamos y producimos realidad.

La pregunta de qué es lo contemporáneo cobró celebridad hace casi una década a través de un texto de Agamben (2009), quien responde con algunas indicaciones que resultan pertinentes para nuestro análisis. La primera evoca las segundas de las unzeitgemäße Betrachtungen (consideraciones intempestivas) nietzscheanas para señalar que aquello que nos es contemporáneo, nos es intempestivo. En dicho texto, Nietzsche (2003) se pronuncia como actual a su época por marcar sus reflexiones un desfasaje con las tendencias del historicismo dialéctico. Si allí el autor de Von Nutzen und Nachteil der Historie für das Leben afirma la desgracia del hombre gregario cuando entra en contacto con la fórmula es war (fue), habrá

15 Para un comentario sobre el concepto del presente en Kant y un análisis sobre la Historik de Koselleck, ver Chignola (2007). 
que destacar el valor del "no aún" que porta el intempestivo ${ }^{16}$. Lo que produce contemporaneidad es, paradójicamente, ese desencuentro en los modos de pensar precisamente el tiempo, no el ajustarse a las orientaciones más corrientes de una época. En ese desvergonzado y anacrónico apartarse, Agamben ve coetaneidad: "La contemporaneidad es, entonces, una singular relación con el propio tiempo, que adhiere a él, y a, a la vez, toma distancia; más precisamente, es aquella relación con el tiempo que adhiere a él a través de un desfasaje y un anacronismo" (Agamben, 2009: párr. 2). Se trataría entonces, de una mirada hacia el presente que detenga el sopor del pasar del tiempo y despierte, en cambio, inquietudes sobre las lecturas que dirigimos a los fenómenos que nos rodean, y de los que también formamos parte. Fracturar el tiempo implica la posibilidad de transformarlo, de observarlo dinámicamente asumiendo ritmos de cambios paralelos no uniformes.

Otra característica que revela lo contemporáneo es una fijación de la mirada, no sobre las luces de una determinada época, sino más bien de su oscuridad. Agamben afirma que esta es una forma activa de adentrarse en las tinieblas de los tiempos. Aquel que en lugar de ser enceguecido por las luces, se siente interpelado en cambio por las sombras, es contemporáneo. Gracias a ello podremos recuperar lo no-vivido del presente cortando la inercia que lo guía:

Esto significa que el contemporáneo no es sólo quien, percibiendo la sombra del presente, aprehende su luz invendible; es también quien, dividiendo e interpolando el tiempo, está en condiciones de transformarlo y ponerlo en relación con los otros tiempos, leer en él de manera inédita la historia, ,citarla“" según una necesidad que no proviene en absoluto de su arbitrio, sino de una exigencia a la que él no puede dejar de responder. Es como si esa luz invisible que es la oscuridad del presente, proyectase su sombra sobre el pasado y éste, tocado por su haz de sombra, adquiriese la capacidad de responder a las tinieblas del ahora. Algo similar debía de tener en mente Michel Foucault cuando escribía que sus indagaciones históricas sobre el pasado son sólo la sombra proyectada por su interrogación teórica del presente. Y Walter Benjamin, cuando escribía que el signo histórico contenido en las imágenes del pasado muestra que éstas alcanzarán la legibilidad sólo en un determinado momento de su historia (Agamben, 2009: párr. 16).

Por eso toda contemporaneidad contiene su propia y eventual quiebra. Pero no en el sentido desolador que implicaría la imagen de una ruina que permanece como el resultado de un desmoronamiento ni como una falla congénita, sino en el de una apertura a otras sen-

16 “(...) el hombre intenta levantarse con todas sus fuerzas de ese gran y pesado lastre que es su pasado. Este no hace sino aplastarle hacia abajo o doblegarle hacia los lados, obstaculizando su marcha como un peso invisible y oscuro que aparentemente alguna vez puede rechazar, como él hace demasiado gustosamente delante de sus semejantes, a fin de despertar su envidia. Por esta razón no puede sino emocionarle, como si de un paraíso perdido se tratase, ver un rebaño pastando o al niño que juega en confiada inconsciencia entre las cercas del pasado y el futuro sin tener aún que rechazar nada de su pasado. Sin embargo, ese juego un día tendrá que ser perturbado, pues demasiado pronto será invocado por el pasado. En ese momento aprenderá la palabra «fue», esa máxima que aparece al hombre para recordarle, por medio de la lucha, el sufrimiento y el tedio, lo que es en el fondo su existencia: un imperfectum que nunca llega a realizarse de modo completo" (Nietzsche, 2003: 41-42). 
sibilidades que rescatan el ímpetu de memorias, para acaso, producir un cambio en el rumbo de las arquitecturas histórico-políticas. Y esto es lo que nos permite pensar el cambio en la historia. Posiblemente explorando en conjunto las experiencias históricas y las disputas por sus reconstrucciones -en palabras de Koselleck "todos los acontecimientos que constituyen una historia y lo que acerca de ello se dice cuando se articula esa historia" (Koselleck, 2001: 73)-, podremos poner de relieve la productividad de las condiciones políticas en que se ocasionan los cambios, indispensables para forjar una mirada crítica del presente.

La definición de lo contemporáneo como aquello que genera una distorsión en su tiempo le concede la posibilidad entonces al pasado nacionalsocialista de pervivir en el siglo XXI a través de diversas manifestaciones. Esto explica que dicho presente pasado no esté sentenciado a desaparecer y que el hecho de que toda historia sea presente, no se traduce en que no esté afectada por el pasado y el futuro. La duración de un pasado presente nunca puede delimitarse, si no es en base a un contexto en particular-que por cierto contemple el espectro de experiencias y expectativas- y que considere los distintos planos en que se desarrolla. El presente se nutre así de un gesto distorsivo que reactualiza la democracia mediante el recuerdo de la atroz experiencia del Holocausto; y de hecho dicha recuperación solo se podrá llevar adelante si la sociedad en cuestión examina, como decía Agamben, su propia oscuridad.

\section{A modo de cierre}

Tras este recorrido, nos encontramos en condiciones de volver sobre la demanda de dejar pasar el pasado, que presentamos de la mano de Nolte. Habrá que señalar primero los pasos que dimos, para dar lugar a tres corolarios. Luego de recuperar los principales argumentos en favor de "dejar pasar el pasado", pudimos observar, gracias al trabajo de Koselleck, los inconvenientes que implicaría postular un tiempo homogéneo que pueda discernir cronológicamente y sin matices el pasado del presente. La noción de Zeitschichten resultó iluminadora por poner de manifiesto distintos niveles en que los acontecimientos puedan intervenir, algo que nos mostró cómo un evento cronológicamente pasado puede ser contemporáneo. Y esto nos llevó inevitablemente a preguntarnos qué significa ser contemporáneo. Respondimos en base a la relevancia de lo intempestivo: el pensamiento debe ser descaradamente desvergonzado, no moderado. Los juicios filosóficos que se expresan sobre estas cuestiones se caracterizan por inquietar y no por buscar una zona de confort; tienen por función generar preguntas y plantear problemas sin descanso. Recordemos la afinidad entre historia y experiencia, en tanto viaje de descubrimiento, que por completo se opone a un estado de reposo.

En cuanto a las conclusiones que se derivan de lo anterior, vale la pena destacar, en primer término, que el presente parece ser pues, una construcción y no un espacio estructural cuya forma se organiza antes del futuro y después del pasado. Lejos de ser un punto fijo, se trata de una disposición que varía de acuerdo a nuestras experiencias. En otras palabras: dicha configuración no es algo dado, sino que es una producción, de allí que podamos asignarle diferentes sentidos. Será entonces hacia los cimientos en que se sostiene la designación de las dimensiones temporales que debemos dirigir nuestra mirada a la hora de pensar nuestra relación con la historia. Esto nos lleva a un segundo corolario: que esas superficies no son autorreferenciales, por el contrario, requieren de su mutua afección -por 
cierto, nunca estable. La definición de aquello que entendemos por pasado, y en todo caso los sucesos que allí pertenecen, tiene como condición sine qua non nuestra pronunciación sobre lo que entendemos por presente y futuro, para lo que intervienen, como bien marcaba Koselleck, nuestros espacios de experiencias y horizontes de expectativas. Se trata de zonas que no se constituyen como totalidades independientes, ni cuyos contenidos y lógicas puedan ser determinados aisladamente. Sin embargo, esto no quiere decir en absoluto que debamos deshacernos de las fronteras temporales. Se trata más bien de indagar los modos en que se conforman -algo que aligera los contenidos que allí residen siempre provisoriamente- y los alcances del valor secuencial, permitiéndonos estar atentos a posibles reformulaciones.

En tercer lugar, este recorrido nos permitió analizar categorías teoréticas, pero en un plano concreto. Y esto tiene una doble consecuencia. Por un lado, al leer la intervención de Nolte a la luz de la Historik koselleckiana, se evidencia que dichos argumentos no pueden sino sostenerse en una teoría de la historia que no contempla la convivencia de múltiples temporalidades. Esta pluralidad, al poner en jaque la concepción de un tiempo lineal y homogéneo, revela la legitimidad de la relativización de las fronteras que separan pasado, presente y futuro. Por otro lado, los pasos dados ponen a prueba la hipótesis de los Zeitschichten con una disputa historiográfica en particular. Se acredita así un fehaciente correlato entre una experiencia en particular y una categoría formal. De esta manera, este ejercicio nos permitió situarnos en una suerte de entre del terreno de la teoría y de la práctica de la historia. Dicho de otro modo: confirmamos que este tipo de situaciones se resisten a ser analizadas como problemas puramente empíricos o formales. Es posible pensar en una direccionalidad que señale que nuestros modelos teóricos requieren de un respaldo material, pero eso no quita que esos modelos no se apoyen en una cierta idea de historia, algo que por cierto, siempre tiene consecuencias políticas. Se explica por ende que haya distintas interpretaciones sobre un mismo acontecimiento que privilegien destacar ciertos aspectos sobre otros.

En suma, estos elementos nos invitan a revisar algunos de los relatos más arraigados en nuestra sociedad, desde los cuales pensar nuestro vínculo con la historicidad. Dicho análisis no solo se emplaza en situaciones harto controvertidas como fue el Historikerstreit, en el que Nolte lanza su pedido de dejar atrás el pasado, sino también en disputas más sigilosas pero no por ello menos políticas, en las que se inscriben prácticas cotidianas que ponen en juego modos específicos de reactualizar el pasado.

\section{Bibliografía}

Adorno, T. (1998). ¿Qué significa superar el pasado? En Educación para la emancipación, (pp. 79-92). Madrid: Morata.

Agamben, G. (29 de marzo de 2009). El tiempo que se escabulle. Clarín.

Bloch, E. (1962). Erbschaft dieser Zeit. Frankfurt am Main: Suhrkamp.

Chignola, S. (2007) Temporalizar la historia. Sobre la Historik de Reinhart Koselleck. ISEGORÍA, N. ${ }^{\circ} 37$, pp. 11-33.

Fuentes, F. y Sebastián, J. (2006). Historia conceptual, memoria e Identidad (II). Entrevista

a Reinhart Koselleck. Revista de libros de la Fundación Caja Madrid, No. 112, pp. 6-10.

Gay, E. (2015). HURGAR EL SILENCIO. SOBRE EL PASADO PASADO DE LA HIS-

TORIA PRESENTE. Ariadna histórica. Lenguajes, conceptos, metáforas, 4, pp. 83-98. 
Habermas, J. (1997). A Berlin Republic: Writings on Germany. Nebraska: University of Nebraska Press.

Habermas, J. (2000). Usos políticos del pasado. En Constelaciones posnacionales. Barcelona: Paidós.

Halbwachs, M. (1997). La mémoire collective. París: Presses Universitaires de France.

Halbwachs, M. (2004). Los marcos sociales de memoria. Caracas: Anthropos Editorial.

Hölscher, L. (2008). Political Correctness: der sprachpolitische Streit um die nationalsozialistischen Verbrechen. Göttingen: Wallstein Verlag.

Hölscher, L. (2009), Semantik der Leere. Grenzfragen der Geschichtswissenschaft. Göttingen: Wallstein Verlag.

Jelin, E. (2006), Memories of state violence: the past in the present. Human Rights Institute, University of Connecticut.

Johann, M. (2010), Gouverner les mémoires. París: Presses Universitaires de France.

Koselleck, R. (1993), Futuro pasado. Barcelona: Paidós.

Koselleck, R. (2001), Los estratos del tiempo. Barcelona: Paidós.

Koselleck, R. (2003), Reinhart Koselleck im Gespräch mit Renate Solbach Öffentlichkeit ist kein Subjekt.

Koselleck, R. (2010), historia/Historia. Madrid: Trotta.

Koselleck, R. (2011), Modernidad, culto a la muerte y memoria nacional. Madrid: Centro de estudios políticos y constitucionales.

Kracauer, S. (2010), Historia. Las últimas cosas antes de las últimas. Buenos Aires: Las cuarenta.

Maier, Ch. (1998), The Unmasterable Past: History, Holocaust, and German National Identity. Cambridge: Harvard University Press.

Nietzsche, F. (2003), Sobre la utilidad y perjuicio de la historia para la vida. Madrid: Biblioteca Nueva.

Nolte, E. (1986), "Die Vergangenheit, die nicht vergehen will. Eine Rede, die geschriben, aber nicht gehalten werden konnte" en Frankfurter Allgemeine Zeitung (Frankfurt). 6-06-1986.

Nolte, E. (2007), Un pasado que no quiere pasar: Una conferencia que, ya escrita, no pudo ser pronunciada. Pasajes, No. 24, pp. 70-75.

Oncina Coves, F. y Villacañas, J. L. (1997), Introducción. En Koselleck, R. y Gadamer, H. G. Historia y hermenéutica. Barcelona: Paidós.

Rauschenberg, N. (2016), El problema de la normalización en tres debates: Historización, Historikerstreit y Goldhagen. Anos 90 - Revista do Programa de Pós-Graduação em História da Universidade Federal do Rio Grande do Sul. v. 23, n. 43, pp. 443-487.

Svampa, L. (2016), Public uses of dictatorial pasts. Visualizations in Germany, Revista História. (São Paulo) No. 35, pp. 1-17.

Todorov, T. (2000), Los abusos de la memoria. Barcelona: Paidós.

Traverso, E. (2012), La historia como campo de batalla. Buenos Aires: FCE.

Wehler, H.U. (1988), Entsorgung der deutschen Vergangenheit?: ein polemischer Essay zum „Historikerstreit“. Múnich: C.H. Beck. 